\title{
GRIT IN MEDICAL PROFESSIONAL EDUCATION STUDENTS
}

\author{
Rusdi Rusli ${ }^{1,2^{*}}$, Nur Ainy Fardana ${ }^{2}$, Wiwin Hendriani ${ }^{2}$ \\ ${ }^{1}$ Psychology Department, Faculty of Medicine, Lambung Mangkurat University, Banjarmasin - INDONESIA \\ 2Doctoral of Psychology Department, Faculty of Psychology, Airlangga University, Surabaya -INDONESIA
}

Submitted: 20 Jun 2020; Final Revision from Author: 16 Oct 2020; Accepted: 29 Dec 2020

\begin{abstract}
Background: Grit is one of the noncognitive predictors that must be owned by medical professional education students in taking professional education. Grit consists of consistency of interest and perseverance of efforts to deal with various conditions that will be encountered in pursuing the educational process. The purpose of this study was to determine how the level of grit in medical internship students in Indonesia.

Methods: This research method used online survey research methods. The procedure for filling out the questionnaire is distributed online and the respondent voluntarily completes the questionnaire with the criteria of the respondent namely active professional medical education students who have completed the profession for at least one year. The survey was responded by 708 medical professional education students from 21 universities that organize medical professional education in Indonesia.

Results: The results of grit categorization for medical professional education students were based on five categories: 2 respondents had very low grit levels and 52 respondents with low grit categories. Meanwhile, 238 respondents had moderate grit levels, 314 respondents were in the high category, and 102 respondents were in the very high category. In addition, there is no difference between the average grit scores of medical professional education students who have passed the study period of one, two, or three years.

Conclusion: There are variations in grit levels obtained from the results of this study. Grit is a strong predictor for work performance and also academic performance. Individuals with a high degree of grit will be more diligent at work, do not easily give up if they fail, and can even make failure as motivation to strive and be more active in achieving goals. Apart from assessing the cognitive abilities of medical students, it is hoped that the assessment of non-cognitive factors in the form of grit measurement at the beginning of selection and during the medical education process can be carried out both at the pre-clinical stage and at the clinical stage. This aims to determine the level of business persistence and consistency of student interest in the medical field.
\end{abstract}

Keywords: grit, medical professional education students

\section{ABSTRAK}

Latar belakang: Grit merupakan salah satu prediktor non kognitif yang harus dimilki oleh mahasiswa pendidikan profesi dokter dalam menempuh pendidikan profesi. Grit terdiri dari konsistensi minat dan ketekunan usaha untuk menghadapi berbagai kondisi yang akan dihadapi dalam menempuh proses pendidikan. Tujuan penelitian ini untuk mengetahui bagaimana tingkat grit pada mahasiswa pendidikan profesi dokter di Indonesia.

*corresponding author, contact: r.rusli@ulm.ac.id 
Metode: Metode penelitian ini menggunakan metode penelitian survei secara daring. Prosedur pengisian kuesioner yakni disebarkan secara daring dan responden secara sukarela mengisi kuesioner tersebut dengan kriteria responden yakni mahasiswa pendidikan profesi dokter aktif yang saat pengisian survei telah menjalani masa profesi minimal satu tahun. Survei ini direspon oleh 708 mahasiswa pendidikan profesi dokter yang berasal dari 21 universitas penyelenggara pendidikan profesi dokter di Indonesia.

Hasil: Hasil kategorisasi grit untuk mahasiswa pendidikan profesi dokter berdasarkan lima kategori yakni 2 responden memiliki tingkat grit yang sangat rendah dan 52 responden dengan kategori grit rendah. Sementara itu, 238 responden memiliki tingkat grit yang sedang, 314 responden dengan kategori tinggi, dan 102 responden dengan kategori sangat tinggi. Selain itu, tidak terdapat perbedaan antara rerata nilai grit mahasiswa pendidikan profesi dokter yang telah melewati masa studi satu, dua, maupun tiga tahun.

Kesimpulan: Terdapat variasi tingkat grit yang diperoleh dari hasil penelitiian ini. Grit merupakan prediktor non kognitif yang kuat untuk performansi kerja dan juga performansi akademik. Individu dengan derajat grit yang tinggi akan lebih tekun dalam menjalani proses pendidikan, tidak mudah menyerah jika mengalami permasalahan atau kegagalan, bahkan dapat menjadikan kegagalan sebagai motivasi untuk semakin berusaha serta giat dalam mencapai tujuan. Selain asesmen kemampuan kognitif pada mahasiswa kedokteran, diharapakan juga dapat dilakukan asesmen faktor non-kogniitf berupa pengukuran grit di awal seleksi dan pada saat proses pendidikan kedokteran baik pada tahapan pre klinik maupun pada tahapan klinik. Hal ini bertujuan untuk mengetahui tingkat ketekunan usaha dan konsistensi minat mahasiswa pada bidang kedokteran.

Kata kunci: grit, mahasiswa pendidikan profesi dokter

\section{PRACTICE POINTS}

- Selain pengukuran faktor kognitif untuk calon mahasiswa kedokteran, dibutuhkan juga pengukuran faktor non kognitif, salah satunya adalah terkait dengan tingkat grit yang dimiliki.

- Grit merupakan faktor non kognitif yang terdiri atas ketekunan usaha dan konsistensi minat yang dapat menunjang performa akademik mahasiswa kedokteran maupun pendidikan profesi dokter.

\section{PENDAHULUAN}

Pada era revolusi industri 4.0, pendidikan kedokteran di Indonesia memiliki tantangan baru untuk menerapkan tiga literasi baru, yaitu data, teknologi, dan kemanusiaan untuk menghasilkan dokter Indonesia yang mampu beradaptasi dan mampu memenuhi kebutuhan nasional dan global. ${ }^{1}$ Pendidikan dokter di Indonesia menetapkan bahwa dalam proses pendidikan dan implementasi kurikulum dilaksanakan dengan meliputi tahapan akademik (fase preklinik) dan tahapan profesi (fase klinik) dengan durasi kurikulum pada tahapan akademik dilaksanakan minimal tujuh semester dan tahapan profesi dilaksanakan 4 (empat) semester. ${ }^{1}$

Berkenaan dengan tujuannya, proses pendidikan kedokteran tidaklah mudah untuk mencapai syarat kualifikasi dan kompetensi yang ditetapkan. Berbagai kesulitan maupun hambatan dapat ditemui oleh para mahasiswa kedokteran baik dalam proses akademik maupun pada fase klinik. ${ }^{2}$ Kompetisi 
sejawat merupakan kesulitan teratas yang dihadapi oleh mahasiswa kedokteran di tahun pertama. Selain itu, kesulitan-kesulitan yang dihadapi oleh mahasiswa kedokteran pada saat proses akademik antara lain kompetisi antarsejawat, kemampuan berbahasa Inggris, pelajaran yang sangat sulit, kurangnya ketersediaan informasi, sumber bahan belajar, peningkatan jumlah tuntutan akademik, kurangnya waktu untuk kehidupan keluarga atau sosial, dan stres ataupun kecemasan selama pendidikan. ${ }^{3}$

Penyusunan beberapa permasalahan yang dihadapi oleh 3.000 mahasiswa kedokteran maupun medical resident dari 5 universitas yang berbeda telah dilakukan oleh ahli. Permasalahan tersebut disusun untuk mengidentifikasi faktor personal dan faktor lingkungan dalam belajar yang dihadapi oleh mahasiswa kedokteran selama proses pendidikan. Kondisi yang ditemui oleh mahasiswa pendidikan profesi dokter di lapangan dapat menjadi sebuah permasalahan bagimahasiswa tersebut. Kondisi yang menjadipermasalahan mahasiswa pendidikan profesi kedokteran menjadi sumber terjadinya burnout pada $50 \%$ mahasiswa kedokteran. ${ }^{4}$

Dalam praktek profesi pendidikan dokter, mahasiswa kedokteran menghadapi tantangan dari berbagi sumber, baik dari pribadi maupun lingkungan sosial. Permasalahan tersebut tidak hanya berkaitan dengan persepsi individu tapi juga terkait dengan tanggung jawab profesi sebagai mahasiswa pendidikan profesi dokter. ${ }^{5}$ Selanjutnya ahli lain menjelaskan bahwa sepanjang karir pendidikan mahasiswa kedokteran akan melalui banyak periode stres dan kesulitan. Faktor-faktor yang berkontribusi pada kemampuan dokter untuk mendukung diri mereka sendiri dan mempertahankan performa akademik dalam melalui masa-masa pendidikan kurang dijelaskan secara lanjut dalam berbagai temuan penelitian. ${ }^{6}$

Terdapat konsekuensi profesional jika permasalahanpermasalahan yang ada dalam tahapan akademik di atas terus berlanjut terjadi pada mahasiswa yaitu seperti empati yang lebih rendah, kecurangan, ketidakjujuran terkait perawatan pasien, masalah mengelola minat, nilai altruistik yang lebih sedikit, pemberian intervensi yang kurang tepat, kemungkinanlebihkeciluntukmelaporkangangguan rekan kerja, mempengaruhi kemungkinan pilihan rekan kerja yang terganggu, mempengaruhi pilihan spesialisasi, kesalahan medis, dan memperoleh nilai yang lebih rendah. Selain itu, terdapat konsekuensi pribadi pada mahasiswa seperti ide bunuh diri, penyalahgunaan atau ketergantungan alkohol, rasa stigma yang lebih besar mengenai masalah kesehatan mental, peningkatan kecelakaan kendaraan bermotor, kesulitan hubungan, dan pikiran untuk menghentikan proses pendidikan. ${ }^{7}$ Lebih lanjut ditemukan bahwa persepsi terhadap permasalahan yang terjadi dalam proses pendidikan profesi dapat menghambat performa akademik mahasiswa bahkan hingga dapat menyebabkan terjadinya keterlambatan studi maupun terhentinya proses studi. ${ }^{8}$

Terdapat beberapa penelitian lainnya yang telah memeriksa prediktor performansi mahasiswa kedokteran dalam menentukan keberhasilan selama menempuh perkuliahan di kedokteran. Salah satu prediktor performansi mahasiswa kedokteran adalah terkait dengan capaian nilai ujian masuk yang terkait dengan kemampuan kognitif. ${ }^{9-14}$

Terdapat kebutuhan untuk menemukan prediktor yang lebih baik selain kemampuan kognitif untuk digunakan sebagai acuan dalam mempertimbangkan calon mahasiswa kedokteran mahasiswa kedokteran. Para peneliti sudah mulai mempertimbangkan variabel nonkognitif yang berpengaruh terhadap kinerja dan performa akademik pada pendidikan kedokteran. Misalnya, kriteria nonakademik yang terkait dengan aplikasi sekolah kedokteran, seperti pernyataan pribadi dan wawancara, serta faktor kepribadian termasuk kesadaran, ekstroversi, dan empati. Selain itu, terdapat kebutuhan untuk menemukan prediktor yang lebih baik selain kemampuan kognitif untuk meningkatkan pemilihan calon mahasiswa kedokteran melihat berbagai potensi permasalahan yang berdampak pada keadaan psikologis kedokteran di fase preklinik maupun klinik. ${ }^{15}$

Faktor lain yang diteliti adalah faktor nonkognitif. Faktor nonkognitif yang dimaksud adalah grit. ${ }^{15} \mathrm{Grit}$ merupakan usaha dan kegigihan mahasiswa untuk mencapai hasil yang diharapkan dan bertahan pada jangka waktu yang panjang walaupun dihadapkan 
dalam tantangan didalam prosesnya. Ia melihat grit pada mahasiswa dilihat dari dua dimensi yaitu konsistensi minat dan ketahanan dalam berusaha. ${ }^{16}$

Penelitian Duckworth melihat grit individu pada dunia pendidikan, sehingga peneliti tertarik untuk menggunakan teori grit ini karena berada pada ranah pendidikan dan sesuai dengan fenomena yang terjadi pada mahasiswa psikologi, karena tidak hanya ingin melihat kegigihan saja tetapi melihat apa saja yang menyebabkan mahasiswa berperilaku grit dilihat dari dua dimensi yaitu konsistensi minat dan ketahanan dalam berusaha untuk mencapai tujuan jangka panjang. ${ }^{9,16,17}$

Hasil penelitian Matero dkk menunjukkan bahwa dari 130 subjek penelitian yang berpartisipasi terhadap penelitian yang dilakukan, 120 subjek berhasil menyelesaikan pendidikan kedokteran dalam waktu 4 tahun yang dikategorikan sebagai lulusan khusus lebih cepat dengan performansi akademik yang optimal dan 10 orang lainnya lulus dengan dengan tepat waktu. Matero dkk mengungkapkan bahwa perbedaan performa akademik dari mahasiswa pendidikan profesi dokter menunjukkan adanya variasi tingkat grit yang dimiliki. ${ }^{15}$

Permasalahan yang dialami oleh mahasiswa kedokteran dapat menghambat performa akademik mahasiswa pendidikan profesi dokter sehingga untuk mengatasi dampak dari permasalahan dalam proses pendidikan profesi, diperlukan usaha serta persistensi dalam menjalani seluruh proses pembelajaran di fase preklinik maupun klinik. Usaha serta persistensi yang dimaksud adalah terkait dengan grit $^{8}{ }^{8}$

Penelitian di atas menunjukkan bahwa mahasiswa pendidikan dokter memiliki grit yang terdiri atas consistency of interest (passion) dan perseverance of effort dalam menjalani pendidikan profesi dengan tujuan untuk dapat mencapai tujuan. ${ }^{16}$ Dalam konteks ini untuk menjadi seorang dokter meskipun menghadapi banyak permasalahan atau kesulitan dalam pendidikan profesi dokter. Penelitian yang dilakukan ini spesifik untuk mengukur tingkat grit pada mahasiswa pendidikan profesi di Indonesia.

Berdasarkan beberapa penelitian di atas, peneliti perlu melakukan penelitian dengan tujuan untuk mengeksplorasi bagaimana tingkat grit mahasiswa pendidikan profesi dokter di Indonesia. Hal ini dianggap penting mengingat bahwa program studi kedokteran merupakan program studi yang memiliki peminat yang tertinggi setiap tahunnya di Indonesia. Grit diharapkan konsisten pada mahasiswa pendidikan profesi dokter agar mahasiswa tersebut dapat menjaga ketekunan usaha dan konsistensi minat pada bidang kedokteran sehingga mampu menunjukkan performa akademik yang optimal. Selain itu, peneliti juga ingin melihat apakah terdapat perbedaan tingkat grit mahasiswa pendidikan profesi dokter antara mahasiswa pendidikan profesi dokter tahun pertama, kedua, maupun ketiga. Selain itu, belum ditemukan penelitian terkait dengan grit pada konteks mahasiswa pendidikan dokter di Indonesia.

\section{METODE}

Penelitian ini menggunakan desain kuantitatif deskriptif. Pengambilan data dalam penelitian ini menggunakan metode survei melalui survei daring menggunakan google form. Prosedur pengisian kuesioner yakni disebarkan secara daring dan responden secara sukarela mengisi kuesioner tersebut dengan Teknik purposive sampling sesuai dengan kriteria subjek. Hal ini dilakukan dengan pertimbangan bahwa ada 86 universitas di Indonesia yang menjalankan program pendidikan dan profesi dokter. Kriteria subjek dalam penelitian ini adalah 1) mahasiswa aktif dalam pendidikan profesidokter, 2) telah melewati masa pendidikan profesi dokter setidaknya selama 1 tahun, 3) bersedia menjadi peserta dalam penelitian ini sesuai dengan formulir informed concent yang disediakan, dan 4) responden melengkapi formulir survei yang didistribusikan melalui online.

Alat ukur yang digunakan dalam penelitian ini menggunakan skala grit yang terdiri atas 12 aitem yang telah melalui proses adaptasi alat ukur. Sebelum proses adaptasi alat ukur dilakukan, peneliti meminta dan memperoleh ijin pada Angela Duckworth dan Quinn ${ }^{17}$ sebagai pengembang teori dan skala grit untuk dialih bahasakan dan digunakan pada konteks mahasiswa pendidikan profesi dokter di Indonesia. Skala tersebut terdiri dari 6 aitem untuk 
aspek consistency of interest (passion) dan 6 aitem untuk aspek perseverance of effort. Setelah proses adapatasi dilakukan uji coba alat ukur dengan melibatkan 305 responden yang sesuai dengan kriteria responden. Pengujian validitas instrumen kuesioner, dilakukan dengan membandingkan nilai factor loading dengan kriteria minimum yakni 0,4 . Diketahui semua nilai loading faktor dari item pertanyaan bernilai lebih besar dari 0,4 (nilai $0,52-0,83$ ) maka disimpulkan bahwa semua aitem pertanyaan yang digunakan dalam alat ukur Grit adalah valid. Statistik uji pada pengujian reliabilitas dengan menggunakan nilai Average Variance Extracted (AVE) dan nilai composite reliability (CR). Pengujian reliabilitas pada tingkat dimensi skala grit dengan menggunakan nilai composite reliability (CR) dan average variance extracted (AVE). Berdasarkan kedua nilai statistik tersebut, disimpulkan bahwa dimensi consistency of interest dan perseverance of effort adalah handal (reliabel) karena dimensi consistency of interest memiliki nilai $\mathrm{CR}=0,75$ nilai $\mathrm{AVE}=0,43$, kemudian dimensi perseverance of effort memiliki nilai $\mathrm{CR}=0,78$ nilai $\mathrm{AVE}=0,48$. Kemudian secara keseluruhan skala grit memiliki nilai $\mathrm{CR}=0,87$ dan $\mathrm{AVE}=0,5$. Sehingga disimpulkan dalam model CFA skala alat ukur Grit, memiliki dimensi-dimensi yang reliabel (handal). Skala grit adaptasi versi Indonesia dapat dilihat pada Tabel 1.

Tabel 1. Skala Grit berdasarkan Angela Duckworth dan Quinn ${ }^{17}$ adaptasi versi Indonesia (Konteks mahasiswa pendidikan profesi dokter)

Dimensi

Consistency of Interest

\section{Item}

Saya sering menetapkan satu tujuan yang hendak saya capai, namun kemudian saya memilih untuk mengejar tujuan lain yang berbeda.

Penugasan baru dari bidang atau departemen terkadang dapat mengalihkan perhatian saya terhadap tugas sebelumnya

Saya menjadi lebih tertarik pada kegiatan baru setiap beberapa bulan kemudian. Minat saya berubah dari tahun ke tahun.

Ketika saya sudah terobsesi pada tugas tertentu, saya bisa tiba-tiba hilang minat pada tugas yang lain.

Saya memiliki kesulitan untuk mempertahankan perhatian pada penugasan yang membutuhkan waktu penyelesaian yang lama.

Perseverance of effort

\author{
Saya telah mencapai tujuan yang membutuhkan waktu bertahun-tahun untuk \\ mengerjakannya. \\ Saya berhasil mengatasi hambatan-hambatan untuk menaklukkan tantangan utama \\ dalam perjalanan studi saya. \\ Saya akan menyelesaikan apapun yang sudah mulai saya kerjakan \\ Rintangan tidak dapat mematahkan semangat saya. \\ Saya pekerja keras \\ Saya adalah orang yang tekun
}

Sebelum mengumpulkan data dari responden, peneliti terlebih dahulu mengajukan uji kelayakan etik ke Komisi Etik Penelitian Kesehatan Fakultas KeperawatanUniversitas Airlangga dan memperoleh persetujuan dengan Ethical Approval No. 2024KEPK. Pengumpulan data dilakukan oleh peneliti pertama secara daring.

\section{HASIL DAN PEMBAHASAN}

TPeneliti memberikan batasan waktu dalam pengisian google form dalam penelitian ini yakni antara tanggal 28 Maret 2020 hingga 7 April 2020. Adapun data responden yang masuk adalah sejumlah 708 mahasiswa pendidikan profesi dokter yang berasal dari 21 universitas penyelenggara pendidikan profesi dokter di Indonesia dengan deskripsi pada Tabel 2 di bawah ini. 
Tabel 2. Deskripsi responden berdasarkan

\section{Variabel Frekuensi Presentase (\%)}

Jenis Kelamin

$\begin{array}{ccc}\text { Laki-laki } & 160 & 22,6 \\ \text { Perempuan } & 548 & 77,4 \\ \text { Usia } & & \\ 20 & 6 & 0,8 \\ 21 & 40 & 5,6 \\ 22 & 210 & 29,7 \\ 23 & 282 & 39,8 \\ 24 & 124 & 17,5 \\ 25 & 32 & 4,5 \\ 26 & 14 & 2,0\end{array}$

Tahun Pendidikan

\begin{tabular}{ccc}
2015 & 8 & 1,1 \\
2016 & 16 & 2,3 \\
2017 & 354 & 50,0 \\
2018 & 330 & 46,6 \\
\hline
\end{tabular}

Tabel 3. Hasil uji deskriptif dimensi perseverance of effort dan consistency of interest

\section{Dimensi Mean Standar Deviasi}

\begin{tabular}{lll} 
Interest & 18,79 & 4,526 \\
Effort & 22,93 & 3,703 \\
\hline
\end{tabular}

Pada pengujian normalitas pada dimensi perseverance of effort dan consistency of interest, masing-masing memperoleh nilai signifikansi 0,096 dan 0,085 . Pada pengujian ANOVA untuk melihat perbedaan nilai grit mahasiswa pada tahun pertama, kedua, dan ketiga diperoleh nilai $F$ hitung $(2,142)$ lebih kecil dari $F$ tabel $(2,618)$. Berdasarkan hasil tersebut, dapat diartikan bahwa tidak ada perbedaan antara grit mahasiswa pada tahun pertama, kedua, dan ketiga. Hasil statistik juga diperoleh nilai signifikansi 0,422 yang nilainya $>0,05$, artinya tidak ada perbedaan nilai grit mahasiswa dilihat dari tahun pendidikannya. Berdasarkan dari kedua hasil hitung statistik tersebut dapat disimpulkan bahwa tidak terdapat perbedaan yang signifikan antara nilai grit mahasiswa berdasarkan lama menjalani pendidikan profesi dokter yaitu pada tahun pertama, kedua, maupun ketiga.
Penelitian ini diharapkan mengungkap mengenai tingkat grit yang dimiliki oleh mahasiswa pendidikan profesi dokter di Indonesia yang sedang menempuh fase klinik. Grit sangat diperlukan untuk menunjang performa akademik mahasiswa kedokteran dengan banyaknya permasalahan dalam proses medical internship. ${ }^{2,6,19,20}$ Untuk mengetahui tingkat grit yang dimiliki responden, peneliti melakukan kategorisasi yang bertujuan untuk menempatkan individu ke dalam kelompok-kelompok yang terpisah secara berjenjang menurut kontinum berdasarkan atribut ukur. ${ }^{18}$ Adapun hasil kategorisasi tingkat grit pada responden dalam penelitian ini dapat dilihat pada Tabel 3.

Tabel 4. Kategorisasi grit pada responden

\begin{tabular}{lcc}
\multicolumn{1}{c}{ Kategori } & Frekuensi & Presentase \\
Sangat rendah & 2 & $0,3 \%$ \\
Rendah & 52 & $7,3 \%$ \\
Sedang & 238 & $33,6 \%$ \\
Tinggi & 314 & $44,4 \%$ \\
Sangat tinggi & 102 & $14,4 \%$ \\
Jumlah & $\mathbf{7 0 8}$ & $\mathbf{1 0 0 \%}$ \\
\hline
\end{tabular}

Hasil survei di atas menjelaskan bahwa tingkat grit mahasiswa pendidikan profesi dokter yang menjadi responden dalam penelitian ini memiliki variasi yang berbeda-beda. Terdapat $0,3 \%$ ( 2 responden) memiliki grit rendah dan 52 responden $(7,3 \%)$ memiliki tingkat grit yang rendah. Sementara terdapat 238 $(33,6 \%)$ responden yang memiliki tingkat grit sedang dan $314(44,4 \%)$ responden memiliki grit kategori tinggi. Adapun responden yang memiliki grit dengan kategori sangat tinggi adalah sejumlah $102(14,4)$ responden.

Secara umum, perbedaan tingkat grit individu dapat disebabkan oleh berbagai faktor pembentuk grit. Terdapat beberapa faktor yang dapat mempengaruhi grit pada seorang individu. Faktor ini dikelompokan menjadi dua yaitu faktor internal dan faktor eksternal. Faktor internal ini terdiri dari interest, practice, purpose dan hope. Sedangkan faktor eksternal yang dapat mempengaruhi grit adalah parenting, the playing field of grit dan culture of grit. ${ }^{16}$ 
Faktor internal yang dapat mendukung perkembangan grit seorang individu yang pertama adalah terkait dengan interest. Interest merujuk pada minat yang dimiliki individu, dan merupakan awal mula untuk mengembangkan grit. Individu yang memiliki interest yang tinggi pada bidang yang individu tersebut geluti cenderung menunjukan gairah yang besar terhadap bidang tersebut, lebih dapat menikmati proses atau kegiatan dibandingkan individu yang kurang memiliki interest pada suatu bidang. Faktor internal kedua yaitu terkait dengan practice. Practice merupakan kapasitas individu untuk dapat belajar dan berlatih secara disiplin. Pada konteks mahasiswa pendidikan profesi dokter, pelatihan kompetensi tentunya diperlukan sehingga tidak terjadi kesalahan prosedur medis atau hal lainnya yang dapat menghambat performansi kerja dan akademik mahasiswa pendidikan profesi dokter. Faktor yang ketiga dan keempat secara internal adalah purpose dan hope. Purpose merupakan salah satu sumber passion dan tanpa adanya purpose, individu dapat kesulitan untuk mempertahankan minat dalam mencapai tujuan jangka panjang yang telah ditetapkan. Memiliki purpose dapat membantu individu untuk mempertahankan minatnya dalam sebuah bidang. Selanjutnya adalah hope, dibutuhkan pada setiap tahap pengembangan grit dan dapat membantu individu untuk fokus hingga akhir. Hope bergantung pada ekspektasi bahwa usaha individu akan mengubah masa depan. Individu yang memiliki hope tinggi, cenderung memiliki ekspektasi bahwa dimasa depan keadaan akan lebih baik. ${ }^{16}$

Faktor selanjutnya adalah faktor eksternal yang meliputi parenting, playing field of grit, dan culture of grit. Parenting mengacu bagaimana pola asuh yang diberikan orangtua pada anaknya membantu menumbuhkan grit. Orangtua dapat mengajarkan interest, practice, purpose dan hope pada anaknya agar menjadi lebih gritty. ${ }^{16}$ Faktor kedua dan ketiga dalam faktor ekstenal yang dapat membentuk grit adalah playing field of grit dan culture of grit. Playing field of grit merupakan regulasi aturan maupun kebiasaan yang dapat menumbuhkan atau meningkatkan grit. Kebiasan yang dimaksud adalah kegiatan yang dilakukan di luar kegiatan utama namun masih berkaitan dengan tujuan utama tersebut. Misalnya kegitan tambahan yang terstruktur yang dirancang untuk memupuk interest, practice, purpose, dan hope.$^{17}$ Dalam konteks dokter muda kegiatan yang dimaksud adalah bimbingan dan pelatihan terkait dengan kompetensi. Calon dokter pada umumnya telah mengkuti kegiatan pelatihan atau bimbingan pengetahuan dan keterampilan profesi dokter sejak fase preklinik sehingga calon dokter bisa saja telah belajar memupuk interest, practice, purpose, dan hope yang kemudian dapat meningkatkan grit calon dokter.

Culture of grit ialah budaya dari lingkungan yang dapat membantu individu dalam mengidentifikasi dan membentuk perilaku grit. Budaya dari lingkungan dapat membantu individu untuk menjadi lebih gritty, ketika individu tersebut bergabung dengan lingkungan atau masyarakat yang gritty. Dalamhal ini lingkungan sosial dapat mempengaruhi grit. Individu dapat meningkatkan grit-nya dengan bergabung dan bergaul dengan orang yang memiliki grit tinggi juga, yaitu individu yang sama-sama memiliki ketekunan usaha dan dapat mempertahankan minatnya untuk mencapai tujuan jangka panjang.

Grit dianggap penting untuk dimiliki oleh mahasiswa pendidikan profesi dokter karena grit merupakan faktor individu dan pribadi yang dapat menentukan bagaimana individu merespon sebuah kondisi ataupun permasalahan yang ada sehingga dengan demikian akan menjadi indikator apakah individu tersebut dapat tetap menampilkan performansi akademik yang optimal atau tidak. Performansi akademik yang dimaksud adalah terkait dengan bagaimana dokter muda dapat menyelesaikan tuntutan akademik yang ada dengan berbagai kemungkinan permasalahan yang ditemui dalam fase tersebut. Terdapat beberapa penelitian yang telah memeriksa prediktor performansi mahasiswa kedokteran dalam menentukan performansi dan keberhasilan selama menempuh perkuliahan di kedokteran. Secara khusus, skor pada Tes Masuk Perguruan Tinggi Kedokteran di Eropa dan Amerika diperoleh dari ujian pemecahan masalah dan berbasis pengetahuan yang digunakan sebagai faktor dalam mengevaluasi kesiapan dan kemampuan untuk penerimaan sekolah kedokteran. Selain itu, skor tes ini digunakan untuk memprediksi kemampuan serta performansi akademik mahasiswa. ${ }^{10-14,19}$ 
Sementara itu untuk di Indonesia, fakultas kedokteran merupakan fakultas yang memiliki peminat dan passing grade tertinggi setiap tahunnya. Jalur untuk masuk fakultas kedokteran di Indonesia antara lain jalur SBMPTN, SNMPTN, dan jalur Mandiri, adapun prediktor kelulusan calon mahasiswa adalah capaian performansi akademik di sekolah menengah serta capaian hasil tes potensi akademik dan kemampuan bidang. ${ }^{22}$ Hal tersebut berarti bahwa prediktor utama dalam memprediksi performa dan hasil akademik mahasiswa kedokteran ialah terkait dengan kapasitas atau kemampuan akademik, sementara faktor-faktor non kognitif lainnya kurang menjadi pertimbangan. Sehingga hasil penelitian ini diharapkan dapat memberikan gambaran terkait dengan peranan salah satu faktor non kognitif yaitu grit pada mahasiswa pendidikan profesi dokter dalam menempuh pendidikan profesi. Oleh karena itu, selain asesmen kemampuan kognitif, diperlukan juga asesmen non kognitif yaitu grit untuk mengukur tingkat ketekunan dan minat yang dimiliki oleh calon mahasiswa kedokteran.

Grit merupakan ketekunan dan konsistensi minat individu untuk melakukan usaha optimal dalam rangka mencapai tujuan jangka panjang. Grit adalah prediktor yang kuat untuk performansi kerja dan juga performansi akademik. Individu dengan derajat grit yang tinggi akan lebih tekun dalam bekerja, tidak mudah menyerah jika mengalami kegagalan, bahkan dapat menjadikan kegagalan sebagai motivasi untuk semakin berusaha serta giat dalam mencapai tujuan. ${ }^{16}$ Grit adalah prediktor yang kuat untuk performansi kerja dan juga performasi akademik. Individu dengan derajat grit yang tinggi akan lebih tekun dalam bekerja, tidak mudah menyerah jika mengalami kegagalan, bahkan dapat menjadikan kegagalan sebagai motivasi untuk semakin berusaha serta giat dalam mencapai tujuan. ${ }^{23}$

Hasil penelitian ini menggambarkan bahwa sebanyak $58,8 \%$ responden memiliki tingkat grit yang tergolong tinggi dan sangat tinggi. Hasil ini sesuai dengan penelitian Matero dkk yang dilakukan terhadap 130 mahasiswa kedokteran yang telah menyelesaikan proses pendidikannya dan menunjukkan hasil bahwa mayoritas sampel penelitiannya mendapatkan skor grit yang tinggi. Grit yang dimiliki oleh dokter pada residen bedah yang memperoleh nilai yang paling tinggi memiliki tingkat grit yang tinggi. ${ }^{19} \mathrm{Grit}$ dibutuhkan oleh para residen dalam menjalani proses pendidikan. ${ }^{2}$ Banyaknya permasalahan dalam pendidikan residen dapat menyebabkan dokter residen menjadi jenuh sehingga dapat menimbulkan permasalahan psikologis. Permasalahan psikologis yang dialami dapat menjadi faktor penghambat performa akademik atau performa kerja para dokter residen. Oleh karena itu, grit dibutuhkan oleh dokter residen dalam menjalani pendidikan. Grit sebagai variabel non kognitif berperan dalam mengatasi kejenuhan karena saat mahasiswa kedokteran memiliki grit yang tinggi, mahasiswa tersebut dapat memikirkan atau melakukan hal-hal positif yang berkaitan dengan pengembangan keprofesian sehingga tidak menganggap bahwa segala proses yang dilakukan dalam ranah akademik adalah hal yang membosankan.

Matero dkk ${ }^{15}$ mengungkapkan bahwa dengan mengetahui tingkat grit dari calon mahasiswa kedokteran, perguruan tinggi dapat meminimalisir atau mencegah permasalahan yang akan terjadi khususnya permasalahan terkait dengan performansi akademik. Hasil penelitian ini sejalan dengan hasil penelitian dari Burkhart dkk dengan subjek mahasiswa medical internship menemukan bahwa individu yang tingkat grit yang lebih rendah cenderung mempertimbangkan untuk meninggalkan atau drop out dari medical internship . Hasil dari penelitian menunjukkan bahwa mahasiswa dengan skor grit lebih tinggi akan lebih mampu menyelesaikan program pendidikan profesi dokter dalam 4 tahun..$^{24}$ Berdasarkan dari hasil penelitian tersebut, menunjukkan bahwa skor grit rendah dapat digunakan oleh sekolah kedokteran untuk membantu memprediksi mahasiswa mana yang mungkin tidak dapat bertahan sampai akhir sekolah kedokteran atau perlu bertahun-tahun tambahan untuk menyelesaikan program profesi. Oleh karena itu, grit tidak hanya memprediksi beberapa ukuran performa akademik, dalam hal ini capaian prestasi akademik, tetapi juga dapat memprediksi hasil penting lainnya seperti ketepatan waktu studi.

Hasil penelitian ini juga menunjukkan tidak terdapat perbedaan nilai rerata grit antara mahasiswa 
pendidikan profesi dokter tahun pertama, kedua, maupun ketiga. Hal ini menggambarkan bahwa tingkat grit mahasiswa pendidikan profesi di Indonesia tidak mengalami perubahan selama program profesi dokter. Hal ini mendukung harapan dari Matero dkk yang menyatakan bahwa grit pada mahasiswa pendidikan profesi dokter merupakan sifat yang diharapkan konsisten dari waktu ke waktu. ${ }^{15}$ Hal ini bertujuan agar mahasiswa dapat menunjukkan performa akademik yang optimal dengan terus menjaga ketekunan dan minat yang dimiliki.

Meskipun demikian, pada tabel 3 menunjukkan bahwa terdapat perbedaan nilai rerata antara consistency of interest dan perseverance of effort pada mahasiswa pendidikan profesi dokter di Indonesia. Nilai consistency of interest (passion) lebih rendah dibanding nilai perseverance of effort. Hal ini tentunya akan menjadi tantangan mengingat passion sangat dibutuhkan untukpengembangan program profesi. ${ }^{8,15}$ Konsistensi minat yang tinggi menunjukkan adanya kemampuan mempertahankan minat pada satu tujuan. Individu yang memiliki konsistensi minat yang tinggi tidak mengubah tujuan yang telah ditetapkan, tidak mudah teralihkan perhatiannya, dan mempertahankan minat dalam waktu jangka panjang. Mahasiswa akan terus melanjutkan studinya dan dapat mempertahankan tujuannya yang telah ditetapkan dari awal dan konsisten dalam jangka waktu yang panjang untuk mendapatkan hasil yang optimal dan memuaskan sehingga mahasiswa tersebut dapat lulus dengan nilai terbaik dan mendapatkan pekerjaan yang sesuai dengan apa yang diinginkan.

Berdasarkan hasil kategorisasi tingkat grit dalam penelitian ini yang cukup bervariasi, tentunya akan menimbulkan konsekuensi positif maupun konsekuensi negatif terhadap performansi dan capaian prestasi akademik mahasiswa pendidikan profesi dokter di Indonesia sesuai dengan pemaparan peneliti terdahulu. Hasil yang diperoleh dalam penelitian ini perlu dilakukan kajian yang lebih lanjut karena responden dalam penelitian ini hanya berasal dari 21 universitas penyelenggara pendidikan profesi dokter di Indonesia dengan sebaran responden yang kurang merata. Oleh karena itu diperlukan penelitian lanjutan yang dapat melakukan pengambilan data secara menyeluruh terkait bagaimana gambaran grit pada mahasiswa pendidikan profesi dokter di Indonesia. Selain itu, penelitian selanjutnya diharapkan dapat mendapat gambaran konsekuensi dari masing-masing tingkatan grit terhadap performa akademik mahasiswa pendidikan profesi dokter di Indonesia.

\section{KESIMPULAN}

Hasil penelitian ini menunjukkan bahwa terdapat variasi tingkatan grit yang dimiliki oleh mahasiswa pendidikan profesi dokter di Indonesia. Variasi yang ditemukan mulai dari yang sangat rendah hingga sangat tinggi. Idealnya, mahasiswa pendidikan profesi dokter harus memiliki tingkat yang grit yang tinggi dalam menempuh proses pendikan profesi dokter. Pengukuran faktor non kognitif yaitu grit dibutuhkan pada saat seleksi maupun pada saat proses pendidikan profesi dokter. Hal ini untuk memberikan gambaran atau prediksi bagaimana tingkat grit yang dapat menunjang performa akademik mahasiswa kedokteran dalam mengikuti proses akademik pada fase pre klinik maupun fase klinik. Sehingga dapat dilakukan langkah antisipasi berupa intervensi bagi mahasiswa yang memiliki tingkat grit yang rendah. Intervensi dapat berupa konseling atau pelatihan pengembangan kepribadian untuk meningkatkan grit yang dimiliki.

\section{SARAN}

Saran yang dapat diberikan melalui hasil penelitian ini yang menjelaskan bahwa masih terdapat variasi tingkat grit mahasiswa pendidikan profesi dokter meskipun tingkat grit mahasiswa pendidikan dokter diharapkan berada pada kategori tinggi untuk menunjang performansi akademik selama fase klinik, yaitu diperlukan evaluasi pengukuran grit secara berkala bagi mahasiswa pendidikan profesi dokter sebagai bahan pertimbangan untuk mengidentifikasi manifestasi dari permasalahan yang dihadapi oleh mahasiswa profesi dokter. Konseling dapat diberikan kepada mahasiswa yang sedang mengalami penurunan tingkat grit untuk mengetahui sumber masalah dan langkah intervensi yang akan ditempuh 
selanjutnya. Saran untuk penelitian selanjutnya ialah agar dapat mengidentifikasi faktor-faktor apa saja yang dapat berpengaruh pada tingkat grit yang dimiliki oleh mahasiswa, khususnya mahasiswa pendidikan profesi dokter.

\section{DAFTAR SINGKATAN}

SNMPTN : Seleksi Nasional Masuk Perguruan Tinggi Negeri

SBMPTN:Seleksi BersamaMasukPerguruan Tinggi Negeri

\section{DEKLARASI KEPENTINGAN}

Para penulis mendeklarasikan bahwa tidak terdapat konflik kepentingan apapun terkait studi pada naskah ini.

\section{KONTRIBUSI PENULIS}

Rusdi Rusli - Peneliti utama, melakukan proses adaptasi skala, analisis data, desain, dan penulis manuskrip

Nur Ainy Fardana - Pembimbing penulis selama proses adaptasi, analisis data, desain, dan terlibat dalam penulisan manuskrip

Wiwin Hendriani - Pembimbing penulis selama proses adaptasi, analisis data, desain, dan terlibat dalam penulisan manuskrip

\section{DAFTAR PUSTAKA}

1. KKI. Standar kompetensi dokter Indonesia. Jakarta: Konsil Kedokteran Indonesia. 2012: 5460.

2. Salles A, Cohen GL, Mueller CM. The relationship between grit and resident wellbeing. The American Journal of Surgery. 2014 Feb 1; 207 (2): 251-4.

3. Almoallim $\mathrm{H}$, Aldahlawi $\mathrm{S}$, Alqahtani $\mathrm{E}$, Alqurashi S, Munshi A. Difficulties facing firstyear medical students at Umm Alqura University in Saudi Arabia. EMHJ-Eastern Mediterranean Health Journal, 2010; 16 (12): 1272-1277.

4. Dyrbye LN, West CP, Satele D, Boone S, Tan
L, Sloan J, Shanafelt TD. Burnout among US medical students, residents, and early career physicians relative to the general US population. Academic medicine. 2014 Mar 1; 89(3): 443-51.

5. Dyrbye LN, Thomas MR, Harper W, Massie Jr FS, Power DV, Eacker A, Szydlo DW, Novotny PJ, Sloan JA, Shanafelt TD. The learning environment and medical student burnout: a multicentre study. Medical education. 2009 Mar; 43(3): 274-82.

6. Halliday L, Walker A, Vig S, Hines J, Brecknell J. Grit and burnout in UK doctors: a crosssectional study across specialties and stages of training. Postgraduate medical journal. $2017 \mathrm{Jul}$ 1; 93(1101): 389-94.

7. Barker BR. Grit \& resilience in learners. Internal Medicine. 2017.

8. Stewart SM, Lam TH, Betson CL, Wong CM, Wong AM. A prospective analysis of stress and academic performance in the first two years of medical school. Medical education. 1999 Apr.

9. Donnon T, Paolucci EO, Violato C. The predictive validity of the MCAT for medical school performance and medical board licensing examinations: a meta-analysis of the published research. Academic Medicine. 2007 Jan 1; 82(1): 100-6.

10. Dunleavy DM, Kroopnick MH, Dowd KW, Searcy CA, Zhao X. The predictive validity of the MCAT exam in relation to academic performance through medical school: a national cohort study of 2001-2004 matriculants. Academic Medicine. 2013 May 1; 88(5): 666-71.

11. Haight SJ, Chibnall JT, Schindler DL, Slavin SJ. Associations of medical student personality and health/wellness characteristics with their medical school performance across the curriculum. Academic Medicine. 2012 Apr 1; 87(4): 476-85.

12. Peskun C, Detsky A, Shandling M. Effectiveness of medical school admissions criteria in predicting residency ranking four years later. Medical education. 2007 Jan; 41(1): 57-64.

13. Veloski JJ, Callahan CA, Xu G, Hojat M, Nash DB. Prediction of students' performances on 
licensing examinations using age, race, sex, undergraduate GPAs, and MCAT scores. Academic Medicine. 2000 Oct 1; 75(10): S28-30.

14. White CB, Kumagai AK, Ross PT, Fantone JC. A qualitative exploration of how the conflict between the formal and informal curriculum influences student values and behaviors. Academic Medicine. 2009 May 1; 84(5): 597-603.

15. Miller-Matero LR, Martinez S, MacLean L, Yaremchuk K, Ko AB. Grit: A predictor of medical student performance. Education for Health. 2018 May 1; 31(2): 109.

16. Duckworth AL, Peterson C, Matthews MD, Kelly DR. Grit: perseverance and passion for long-term goals. Journal of personality and social psychology. 2007 Jun; 92(6): 1087.

17. Duckworth AL, Quinn PD. Development and validation of the Short Grit Scale (GRIT-S). Journal of personality assessment. 2009 Feb 17; 91(2): 166-74.

18. Azwar S. Reliabilitas dan validitas. Yogyakarta: Pustaka Belajar Offset. 2012.
19. Cortez AR, Winer LK, Kim Y, Hanseman DJ, Athota KP, Quillin III RC. Predictors of medical student success on the surgery clerkship. The American Journal of Surgery. 2019 Jan 1; 217(1): 169-74.

20. Ray R, Brown J. Reassessing student potential for medical school success: distance traveled, grit, and hardiness. Military Medicine. $2015 \mathrm{Apr}$ 1; 180(suppl_4): 138-41.

21. Shih AF, Maroongroge S. The importance of grit in medical training. Journal of Graduate Medical Education. 2017; 9(3): 251-254.

22. Riset, K. Teknologi dan Pendidikan Tinggi. Peraturan Menteri. 2018.

23. Suzuki Y, Tamesue D, Asahi K, Ishikawa Y. Grit and work engagement: A cross-sectional study. PloS one. 2015 Sep 3; 10(9): e0137501.

24. Burkhart RA, Tholey RM, Guinto D, Yeo CJ, Chojnacki KA. Grit: a marker of residents at risk for attrition?. Surgery. 2014Jun 1; 155(6): 1014-22. 